\title{
Comprehensive approach to weaning in difficult-to-wean infantile and juvenile- onset glycogen-storage disease type II patients: a case series
}

Lingling $\mathrm{Xu}^{1+}{ }^{1}$, Hongjun $\mathrm{Ba}^{2 \dagger}$, Yuxin Pei ${ }^{1}$, Xueqiong Huang ${ }^{1}$, Yujian Liang ${ }^{1}$, Lidan Zhang ${ }^{1}$, Huimin Huang ${ }^{1}$, Cheng Zhang ${ }^{3}$ and Wen Tang ${ }^{1 *}$

\begin{abstract}
Background: Glycogen storage disease type II (GSD II) is caused by acid alpha-glucosidase (GAA) deficiency. Both infantile-onset and juvenile-onset GSD II lead to proximal muscle weakness and respiratory insufficiency and require mechanical ventilation. However, GSD II is also independently associated with delayed weaning from mechanical ventilation. This study aimed to describe a comprehensive approach including sequential invasive-noninvasive mechanical ventilation weaning and enzyme replacement therapy (ERT) in patients with weaning difficulties.

Case presentation: We studied six difficult-to-wean GSD II (three juvenile-onset, three infantile-onset) patients at the First Affiliated Hospital, Sun Yat-sen University from October 2015 to December 2017. Difficulty in weaning was defined as follows: the need for more than three spontaneous breathing trials or more than 1 week to achieve successful weaning. All patients received comprehensive treatment including sequential invasive-noninvasive mechanical ventilation weaning, ERT and general treatment. Recombinant human acid alpha-glucosidase enzyme therapy (20 mg/ kg every 14 days) was used after diagnosis, and Patients $1-6$ received ERT for 15.5, 4.5, 2, 2.5, 17, and 2 months, respectively. The therapeutic effect of the comprehensive treatment was observed.

The patients' respiratory function and limb muscle strength improved after each ERT session. Patients who successfully completed a spontaneous breathing trial could proceed to extubation, and then start non-invasive ventilation. The patients' age range at initial mechanical ventilation was 3-47 (median 26.5) months, duration of invasive ventilation was 1-36 (median 2.75) months, and duration of noninvasive ventilation was 0-0.6 (median 0.05) month. The patients' nutritional status improved after enhanced nutritional support. Patients 2, 3, and 5 were successfully weaned off the ventilator. Patient 1 underwent tracheal intubation after six weaning failures, and Patients 4 and 6 died after therapy was abandoned by their parents.

\footnotetext{
* Correspondence: tangwen@mail.sysu.edu.cn

${ }^{\dagger}$ Lingling Xu and Hongjun Ba contributed equally to the manuscript and should be considered as co-first author.

${ }^{1}$ Department of PICU, The First Affiliated Hospital, Sun Yat-Sen University, 58

Zhongshan Second Road, Guangzhou, Guangdong 510080, People's

Republic of China

Full list of author information is available at the end of the article
}

(c) The Author(s). 2019 Open Access This article is distributed under the terms of the Creative Commons Attribution 4.0 International License (http://creativecommons.org/licenses/by/4.0/), which permits unrestricted use, distribution, and reproduction in any medium, provided you give appropriate credit to the original author(s) and the source, provide a link to the Creative Commons license, and indicate if changes were made. The Creative Commons Public Domain Dedication waiver (http://creativecommons.org/publicdomain/zero/1.0/) applies to the data made available in this article, unless otherwise stated. 
(Continued from previous page)

Discussion and conclusions: Male sex, GSD II type, and the presence of malnutrition and neurological impairment may predict poor respiratory outcomes. The above-described comprehensive sequential invasivenoninvasive mechanical ventilation weaning strategy may increase the success rate of weaning from mechanical ventilation.

Keywords: Enzyme replacement therapy, Glycogen storage disease type II, Respiratory failure, Sequential invasive-noninvasive ventilation, Weaning

\section{Background}

Glycogen storage disease type II (GSD II), also known as Pompe disease, is an autosomal recessive inherited metabolic disorder caused by a deficiency of acid alpha-glucosidase (GAA); it manifests as muscle weakness, hypertrophic cardiomyopathy, and respiratory failure [1]. GAA deficiency leads to systemic glycogen accumulation in the lysosomes of skeletal muscle, motor neurons and smooth muscle, which causes progressive proximal muscle and respiratory muscle weakness. GSD II is categorized into early-onset (infantile-onset) and late-onset (juvenile-onset and adult-onset) GSD II by the age at onset. Infantile-onset GSD II is the most severe form of the disease, and is characterized by hypertrophic cardiomyopathy, muscle weakness and early death, generally caused by cardio-respiratory insufficiency as natural history. Both infantile-onset and juvenile-onset GSD II lead to proximal muscle weakness and respiratory insufficiency and require mechanical ventilation. Limb weakness, respiratory muscle weakness and diaphragm weakness are independently associated with delayed weaning from mechanical ventilation [1-3]. Prolonged mechanical ventilation is known to result in increased pulmonary complications and costs [4], as well as increased lengths of hospital stay and clinical scores.

Enzyme replacement therapy (ERT) cannot improve muscle strength and respiratory function, and result in weaning from the ventilator in all patients. Recombinant human acid alpha-glucosidase enzyme therapy can improve patients' muscle strength and respiratory function $[5,6]$. Sequential invasive-noninvasive ventilation is useful in treating patients with invasive mechanical ventilation weaning failure [7]. Additionally, symptomatic and supportive treatment with appropriate breathing exercises, as well as expectoration and strengthening nutrition can aid in weaning from ventilation. In this study, we aimed to describe a comprehensive approach including sequential invasive-noninvasive mechanical ventilation weaning and ERT for patients with weaning difficulty.

\section{Case presentation}

\section{Subjects}

The inclusion criteria for enrollment in the present study were: 1) Presence of the following clinical manifestations of the disease: cardiac hypertrophy or hypertrophic cardiomyopathy, progressive weakness of skeletal muscle, recurrent respiratory infection; 2) GAA activity in peripheral blood leukocytes lower than normal; 3) GSD II confirmed by GAA gene analysis; 4) Presence of difficulty in weaning, defined as $[2,33]$ : the need for more than three spontaneous breathing trials or more than 1 week for successful weaning achievement. Weaning success was defined as a patient's ability to tolerate spontaneous breathing for more than $48 \mathrm{~h}$; and 5) mechanical ventilator use duration longer than 14 days and difficulties in weaning from mechanical ventilation.

We retrospectively analyzed six difficult-to-wean GSD II patients at the pediatric intensive care unit (ICU) of the First Affiliated Hospital, Sun Yat-sen University from October 2015 to December 2017.

The patients' detailed clinical data are presented below (Table 1).

Patient 1, a 32-month-old girl with the juvenile form of GSD II, was hospitalized with difficulties in weaning from the ventilator. She had suffered from muscular weakness since age 15 months, when she started walking unsteadily. She lost the ability to walk at 26 months. She was admitted to our hospital using a transport ventilator. She exhibited a repeated and weak cough, and was susceptible to recurrent chest infections. Oral sedative use was required for chest computed tomography performance. After sedation with $0.5 \mathrm{ml} / \mathrm{kg}(5 \mathrm{ml})$ of oral chloral hydrate, she developed respiratory muscle weakness and ventilator failure, and required invasive ventilation at age 30 months (Tables 1 and 2).

Patient 2, a 24-month-old boy with the juvenile form of GSD II, who presented with difficulties in weaning from the ventilator at age 23 months, was admitted to our hospital for the first time using a transport ventilator. He walked slowly and began having repeated respiratory infections at age 20 months. He was successfully withdrawn from mechanical ventilation without ERT at the first admission, because he was not diagnosed with GSD II. His symptoms improved, and he was discharged home. At age 30 months, he was admitted to our hospital again due to respiratory failure and required invasive ventilation again (Tables 1 and 3). 


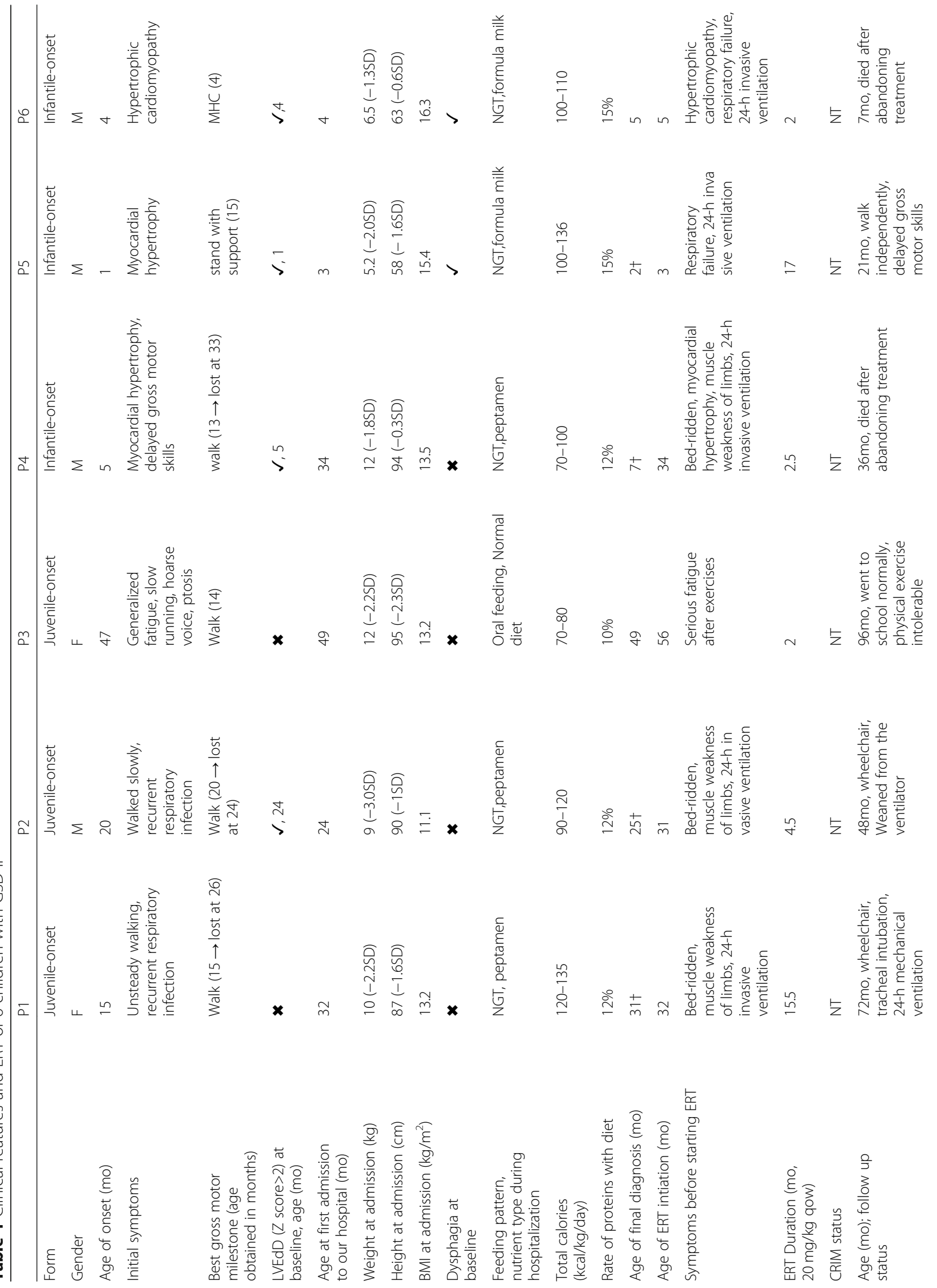




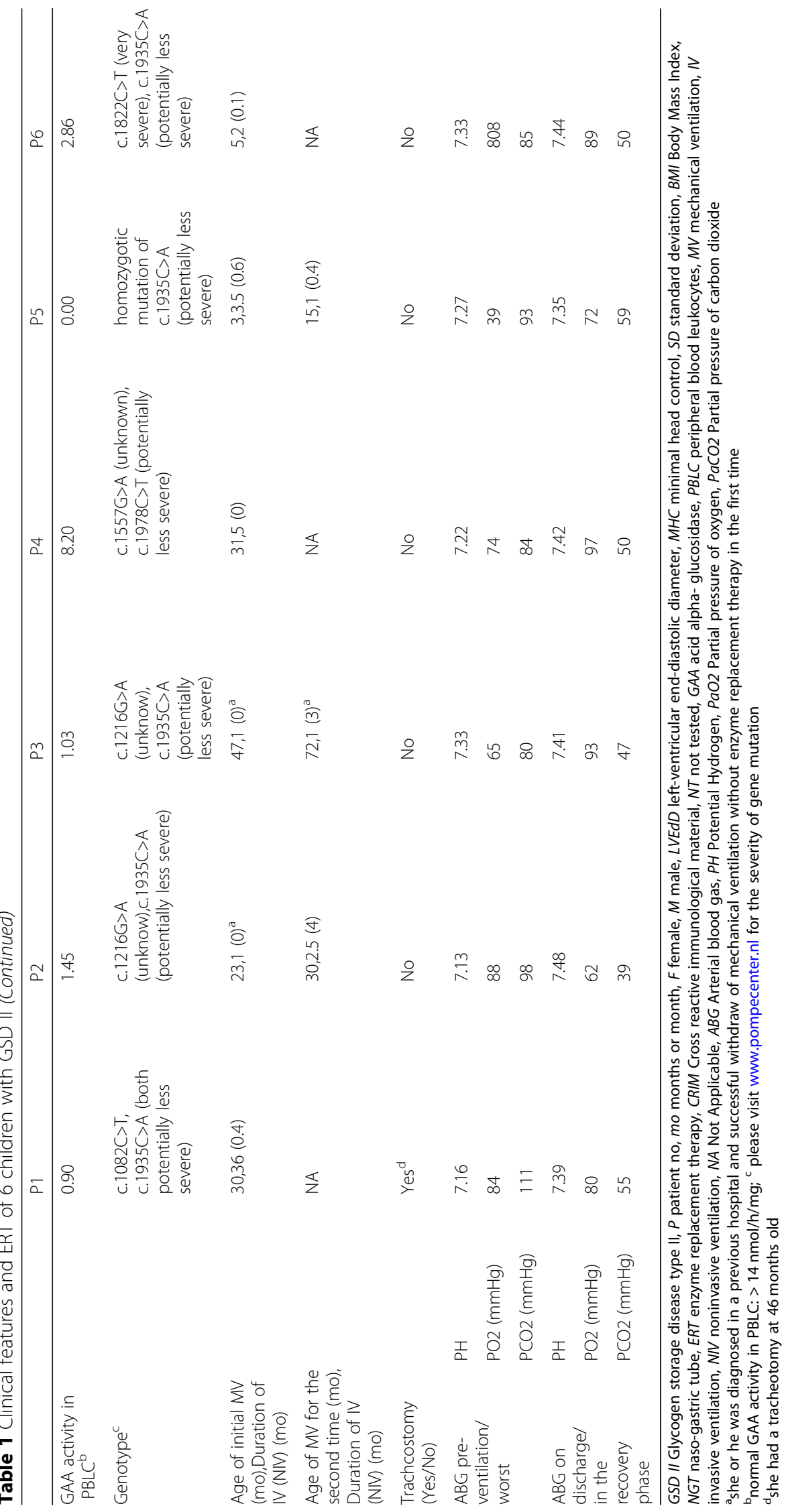


Table 2 Changes in respiratory and muscle strength of $\mathrm{P} 1$ (juvenile-onset) after enzyme replacement therapy

\begin{tabular}{|c|c|c|c|c|c|}
\hline \multirow{2}{*}{$\begin{array}{l}\text { Months } \\
\text { of ERT } \\
\text { ( } 28 \text { days/ } \\
\text { month) }\end{array}$} & \multicolumn{3}{|c|}{ Proportion of ventilator time } & \multicolumn{2}{|c|}{ MRC scale } \\
\hline & $\begin{array}{l}\text { Invasive } \\
\text { BiPAP\% }\end{array}$ & $\begin{array}{l}\text { Invasive } \\
\text { CPAP\% }\end{array}$ & $\begin{array}{l}\text { NIV\% or } \\
\text { time }\end{array}$ & UL & $\mathrm{LL}$ \\
\hline 0.0 & 100 & 0 & $10 \mathrm{~min}$ & 3 & $3+$ \\
\hline 0.5 & 29 & 71 & 0 & 3 & $3+$ \\
\hline 1.0 & 21 & 79 & $30 \mathrm{~min}$ & 4 & $3+$ \\
\hline 1.5 & 14 & 86 & 0 & $4+$ & $3+$ \\
\hline 2.0 & 0 & 100 & 0 & 5- & 4- \\
\hline $2.5-3.5$ & 20 & 80 & 0 & $5-$ & 4 \\
\hline $4.0-5.0$ & 0 & 100 & 0 & 5 & $5-$ \\
\hline $5.5^{\mathrm{a}}$ & 79 & 21 & $2 \mathrm{~h}$ & 5 & 5 \\
\hline 6.0 & 7 & 93 & 0 & 5 & 5 \\
\hline $6.5-7.0$ & 0 & 100 & 0 & 5 & 5 \\
\hline 7.5 & 14 & 86 & $2 d$ & 5 & 5 \\
\hline $8.0-8.5$ & 15 & 85 & 0 & 5 & 5 \\
\hline 9.0 & 64 & 14 & $3 d$ & 5 & 5 \\
\hline $9.5-10.5$ & 6 & 94 & 0 & 5 & 5 \\
\hline 11.0 & 57 & 0 & $6 d$ & 5 & 5 \\
\hline $11.5-13.5$ & 37 & 63 & 0 & 5 & 5 \\
\hline $14.0-14.5^{\mathrm{a}}$ & 100 & 0 & 0 & 5 & 5 \\
\hline $15.0^{\mathrm{b}}$ & 29 & 0 & 0 & 5 & 5 \\
\hline
\end{tabular}

ERT enzyme replacement therapy, $P$ patient no, BiPAP Biphasic positive airway pressure, min minutes, $h r$ hours, $d$ days, CPAP Continuous positive airway pressure, NIV noninvasive ventilator, MRC medical research council, UL Upperlimb muscle strength, $L L$ lower-limb muscle strength

${ }^{\text {a }}$ Pulmonary infection; ${ }^{\mathrm{b}}$ Tracheotomy

Patient 3 with the juvenile form of GSD II is the older sister of Patient 2. She experienced generalized fatigue, showed bilateral ptosis, ran slowly, and spoke with a hoarse voice at age 47 months. She was transferred to our hospital at age 49 months due to pneumonia and respiratory failure from another hospital using a transport ventilator (Table 1).

Patient 4, a 34-month-old boy with the infantile form of GSD II, presented with pneumonia complicated with

respiratory failure and was admitted to our hospital using a transport ventilator. He had left ventricular hypertrophy at age 5 months, began having repeated respiratory infections at age 12 months, and while he could walk at 13 months, he lost the ability at 33 months (Table 1).

Patient 5, a 3-month-old boy with the infantile form of GSD II, presented with ventricular hypertrophy at age 1 month and had repeated respiratory infections when he was admitted to our hospital for the first time. His condition quickly evolved into pneumonia complicated with respiratory failure on day 3 after admission, requiring invasive ventilation. After 4
Table 3 Changes in respiratory and muscle strength of P 2 (juvenile-onset) after enzyme replacement therapy

\begin{tabular}{|c|c|c|c|c|c|}
\hline \multirow{2}{*}{$\begin{array}{l}\text { Months of ERT } \\
\text { (28 days/month) }\end{array}$} & \multicolumn{3}{|c|}{ Proportion of ventilator time } & \multicolumn{2}{|c|}{ MRC scale } \\
\hline & $\begin{array}{l}\text { Invasive } \\
\text { BIPAP\% }\end{array}$ & $\begin{array}{l}\text { Invasive } \\
\text { CPAP\% }\end{array}$ & NIV\% & UL & $\mathrm{LL}$ \\
\hline 0.0 & 100 & 0 & 0 & 4 & 3 \\
\hline 0.5 & 29 & 71 & 0 & 4 & $3+$ \\
\hline 1.0 & 21 & 79 & 0 & 4 & $3+$ \\
\hline 1.5 & 14 & 86 & 0 & $4+$ & $3+$ \\
\hline 2.0 & 0 & 90 & 10 & $4+$ & $3+$ \\
\hline 2.5 & 14 & 50 & 36 & $4+$ & $3+$ \\
\hline 3.0 & 0 & 0 & 100 & $4+$ & $3+$ \\
\hline 3.5 & 0 & 0 & 100 & $5-$ & $3+$ \\
\hline 4.0 & 0 & 0 & $50^{a}$ & $5-$ & $3+$ \\
\hline
\end{tabular}

ERT enzyme replacement therapy, $P$ patient no, BIPAP Biphasic positive airway pressure, CPAP Continuous positive airway pressure, NIV noninvasive ventilation, MRC medical research council, UL Upper-limb muscle strength, LL lower-limb muscle strength

at night

months of undergoing ERT, he was successfully weaned off mechanical ventilation. His symptoms improved, and he was discharged home at age 7 months. At age 15 months, he was admitted to our hospital again due to respiratory failure and required invasive ventilation again (Tables 1 and 4).

Patient 6, a 4-month-old boy with the infantile form of GSD II, presented with hypertrophic cardiomyopathy and pneumonia complicated with respiratory failure and was admitted to our hospital. He required invasive ventilation on the day of admission (Table 1).

All six patients had a full-term normal delivery with no history of neonatal asphyxia. The parents of these patients did not have a consanguineous marriage and their mothers were all healthy with normal pregnancies and deliveries. Patients 2 and 3 belonged to the same family, and the other patients had no family history of neuromuscular disorders.

Table 4 Changes in respiratory and muscle strength of P5 (infantile-onset) after enzyme replacement therapy

\begin{tabular}{|c|c|c|c|c|}
\hline \multirow{2}{*}{$\begin{array}{l}\text { Months of ERT } \\
\text { (28 days/month) }\end{array}$} & \multicolumn{2}{|c|}{ Proportion of ventilator time } & \multicolumn{2}{|c|}{ MRC scale } \\
\hline & $\begin{array}{l}\text { Invasive } \\
\text { BIPAP\% }\end{array}$ & NIV \% & UL & $\mathrm{LL}$ \\
\hline 0.0 & 100 & 0 & 4- & 4- \\
\hline $0.5-4.5$ & 100 & 0 & 4- & 4- \\
\hline $4.5-5.5$ & 0 & 100 & 4 & 4 \\
\hline$>4.5^{\mathrm{a}}$ & 0 & 0 & $4+$ & $4+$ \\
\hline
\end{tabular}

$E R T$ enzyme replacement therapy, $P$ patient no, BIPAP Biphasic positive airway pressure, NIV noninvasive ventilation, $M R C$ medical research council, UL Upperlimb muscle strength, $L L$ lower-limb muscle strength at home 


\section{Therapeutic methods General treatment}

The patients with pneumonia received empirical antiinfection therapy. The anti-infection therapeutic regimen was adjusted according to the disease etiology. The patients were kept in the semi Fowler's position for ventilator-associated pneumonia prevention. Routine nursing measures and prone-position ventilation were performed. After watching live-action video and doing exercises following medical staff, the patients who were older than 2 years old, were encouraged to practice independent expectoration, and to perform breathing exercises and undergo respiratory muscle training with their parents. Enhanced enteral and part parenteral nutrition were administered. The nutritional goal of enteral nutrition without and with parenteral nutrition were reached at more than $70 \mathrm{kcal} / \mathrm{kg} /$ day. We used music therapy, increased the number of ICU visiting hours, enhanced patients' comfort levels, and encouraged them to cooperate with the weaning efforts, so as to enhance their confidence in weaning.

\section{Treatment of primary disease}

All patients diagnosed with GSD II whose parents signed an informed consent form were included. Approval from the ethics committee of the First Affiliated Hospital, Sun Yat-sen University was obtained. ERT with recombinant human acid alpha-glucosidase (rhGAA, alglucosidase alfa, Myozyme ${ }^{\circ}$ Sanofi Genzyme) is available for the treatment of GSD II at our hospital. At 1-27 months post diagnosis, the patients received biweekly infusions of $20 \mathrm{mg} / \mathrm{kg}$ recombinant human $\alpha-1,4$-glucosidase. Patients 1-6 received ERT for 15.5, 4.5, 2, 2.5, 17 and 2 months, respectively. Using the Medical Research Council (MRC) scale, muscle strength, as well as the ventilator mode and parameters were assessed at the baseline and 1 month after each ERT session. These patients were followed-up for a median of 7.25 months (range, 2 to 16 months).

\section{Sequential invasive-noninvasive mechanical ventilation weaning strategy}

All the patients underwent a routine procedure during ventilator weaning as follows: 1) Lung and systemic infection control without complications was achieved; 2) When the low parameter invasive biphasic positive airway pressure level was well-tolerated, the invasive continuous positive airway pressure (CPAP) mode was used. The indications for non-invasive mechanical ventilation were: 1 ) More than $12 \mathrm{~h}$ of invasive CPAP were tolerated [positive end-expiratory pressure (PEEP) $\leq 4$ $\mathrm{cm} \mathrm{H}_{2} \mathrm{O}$; 2) pressure support $\leq 6 \mathrm{~cm} \mathrm{H}_{2} \mathrm{O}$; 3) Arterial blood $\mathrm{pH}$ before weaning of 7.3-7.5 was achieved, as were a partial pressure of oxygen $\left(\mathrm{PaO}_{2}\right) \geq 60 \mathrm{mmHg}$ and partial pressure of carbon dioxide $\left(\mathrm{PaCO}_{2}\right) 30-55$ mmHg; 4) When patients satisfied the above-stated conditions, noninvasive positive pressure ventilation was used immediately after extubation (sequential invasive-noninvasive strategy); 5) Weaning was performed in the morning, as long as the quality of sleep the previous night was good; 6) Patients were required to be conscious and able to independently cough and expectorate, and ERT was ideally used within the last week; and 7) A total of $1-2 \mathrm{mg} / \mathrm{kg}$ of methylprednisolone 20 min before weaning was intravenously provided to reduce the degree of laryngeal edema in patients who required invasive ventilation for longer than 1 month.

\section{Matters needing attention during weaning from mechanical ventilation}

1) Choosing an appropriately sized nasal mask or mouth-nose mask with good air tightness for patients; 2) Humidified ventilation use to improve sputum expectoration; 3) Administration of Budesonide and Salbutamol by drug aerosol inhalation for the alleviation of laryngeal edema and prevention of airway spasms; and 4) Close monitoring of vital signs and blood gas analysis after weaning.

\section{Criteria for weaning failure}

1) Occurrence of respiratory distress and hemodynamic instability within a week after invasive ventilator use, with a respiratory rate greater than 70 breaths per minute or an increase of 30 breaths per minute, heart rate greater than 180 beats per minute or an increase of 20 beats per minute, and a change in systolic blood pressure $\geq 20 \%$; 2) Arterial blood gas analysis showed a $\mathrm{pH} \leq 7.30$, arterial oxygen saturation $\left(\mathrm{SaO}_{2}\right) \leq 80 \%$, $\mathrm{PaCO}_{2}>75 \mathrm{mmHg}, \mathrm{PaO}_{2}<60 \mathrm{mmHg}$ or $\mathrm{PaO}_{2} /$ Fraction of inspired oxygen $\left(\mathrm{FiO}_{2}\right)<200$, or disturbance of consciousness.

\section{Results}

With comprehensive treatment, the respiratory muscle strength of all patients was improved. Their nutritional status also improved after enhanced nutritional support was provided. Their detailed clinical data are shown in Tables 1, 2, 3, 4, 5.

Patient 1: All six attempts to wean from invasive ventilation and start non-invasive ventilation failed. The major manifestations of weaning failure included: (1) Body temperature $\geq 38.0^{\circ} \mathrm{C}$ within $48 \mathrm{~h}$ after weaning from invasive ventilation; (2) Difficulty in expectoration with respiratory muscle fatigue, increased rale rates as observed on lung auscultation, and $\mathrm{PaCO}_{2} \geq 60 \mathrm{mmHg}$; (3) Mental problems during ventilator-dependence, such as emotional stress, anxiety and depression; and (4) Tolerance achievement within 1-6 days of each non-invasive 
Table 5 Cardiac structure and function after ERT in children with infantile GSD ॥

\begin{tabular}{|c|c|c|c|c|c|c|c|c|c|}
\hline \multirow[t]{2}{*}{$\begin{array}{l}\text { Months of ERT } \\
\text { (28 days/month) }\end{array}$} & \multicolumn{3}{|c|}{ Age (months) } & \multicolumn{3}{|c|}{$\begin{array}{l}\text { Interventricular septal } \\
\text { thickness }(\mathrm{mm})\end{array}$} & \multicolumn{3}{|c|}{$\begin{array}{l}\text { Left ventricular } \\
\text { ejection fraction(\%) }\end{array}$} \\
\hline & $P 4^{\mathrm{a}}$ & P5 & $P 6^{a}$ & $P 4^{a}$ & P5 & $P 6^{a}$ & $\overline{P 4^{a}}$ & P5 & $P 6^{a}$ \\
\hline 0.0 & 34 & 3 & 5 & 12 & 12 & 17 & 60 & 58 & 32 \\
\hline 1.0 & 35 & 4 & 6 & 11 & 9 & 14 & 63 & 63 & 45 \\
\hline 2.0 & 36 & 5 & 7 & - & 7 & 11 & - & - & 48 \\
\hline 17.0 & - & 22 & - & - & 5 & - & - & 75 & - \\
\hline
\end{tabular}

ERT enzyme replacement therapy, GSD // Glycogen storage disease type II, $P$ patient no

a patient died after abandoning treatment; - untreated

ventilation, upon which emergency intubation and mechanical ventilation were finally required. After six weaning failures, the patient underwent tracheal intubation and mechanical ventilation after more than 1 year (30 doses) of ERT administration. Before ERT, muscle strength testing using the MRC scale was performed, showing a score of 3 for the upper limb and $3+$ for the lower limb. The patient could not sit. The muscle strength of her limbs improved after each ERT session, with the strength returning to normal after 5 months of ERT, and she could sit independently. Ventilator support was gradually reduced to half ventilator support through reductions in the invasive CPAP level after 2 months of ERT and then reductions in the PEEP level. Several minutes or hours of tracheal intubation in a spontaneous breathing state with oxygen supplementation were allocated every day to respiratory muscle training. From the time of disease onset, the patient received invasive mechanical ventilation for 30 months and intermittent non-invasive mechanical ventilation for 11 days (Tables 1 and 2).

Patient 2: The patient received invasive mechanical ventilation twice due to pneumonia. Using the sequential invasive-noninvasive strategy, he was successfully weaned from ventilation without ERT the first time (age 23 months) and after 3 months of ERT the second time (age 30 months). Before ERT, muscle strength testing using the MRC scale showed an upper limb score of 4 and lower limb score of 3 . The patient could sit but was not very stable. He could not stand or walk. The muscle strength of his limbs improved after each ERT session; after 4 months of ERT, he showed an upper limb score of 5- and lower limb score of 3+. He could sit independently. From the time of disease onset, the patient received invasive mechanical ventilation for 3.5 months and intermittently required non-invasive mechanical ventilation at home at night (Tables 1 and 3).

Patient 3: She received invasive mechanical ventilation twice due to pneumonia. Using the sequential invasivenoninvasive strategy, mechanical ventilation was successfully withdrawn for the first time before diagnosis (age 49 months) and treatment with ERT (age 56 months). She received 2 months of ERT due to limb weakness when she was aged 56 months. She required invasive mechanical ventilation due to pneumonia and respiratory failure for the second time for a period of 27 days. She was also successfully weaned from ventilation without ERT this time (age 72 months). Her 6-min walk test result increased from $100 \mathrm{~m}$ at the baseline to $300 \mathrm{~m}$ after 2 months of ERT. From the time of disease onset, she received invasive mechanical ventilation for nearly 2 months and non-invasive mechanical ventilation for 3 months (Table 1).

Patient 4: He required invasive mechanical ventilation due to pneumonia and respiratory failure. Weaning failure from invasive ventilation was confirmed after 2.5 months of ERT, and he died after treatment abandonment (Tables 1 and 5).

Patient 5: ERT was initiated in this patient after diagnosis, and he required invasive mechanical ventilation twice due to pneumonia. Using the sequential invasivenoninvasive strategy, he was successfully weaned from ventilation the first (age 3 months) and second (age 15 months) times. From the time of disease onset, he received invasive mechanical ventilation for about 4.5 months and non-invasive mechanical ventilation for about 1 month. He demonstrated features of mild movement retardation. He was able to raise and support his head at age 9 months, sit independently at 12 months old, and stand with support at 15 months (Tables 1, 4 and 5).

Patient 6: He required invasive mechanical ventilation due to pneumonia and respiratory failure. He showed invasive ventilation weaning failure after 2 months of ERT and died after treatment abandonment (Tables 1 and 5).

\section{Discussion and conclusions}

GSD II patients experience progressive muscle weakness, especially in the limbs and trunk, including in the muscles that control breathing, and may eventually require mechanical ventilation. Predictors of poor respiratory outcomes include male sex, disease duration, and overall neurological impairment $[8,9]$. The typical manifestations of infantile-onset GSD II are cardiomegaly at an early stage [6], and quick progression to cardiopulmonary insufficiency. The incidence of pulmonary infection or dyspnea in infantile-onset GSD II is $78 \%$; $29.2 \%$ (49/168) of such patients develop respiratory failure 
and require mechanical ventilation [10]. Broomfield et al. reported that $27 \%(9 / 33)$ of infantile-onset GSD II patients had respiratory failure and the need for longterm ventilation [11], which are associated with high morbidity and mortality. Juvenile-onset GSD II lacks major cardiac involvement and presents with slowly progressive myopathy of the limb-girdle muscles, trunk muscles, and diaphragm [12]. The typical manifestations of juvenile-onset GSD II are unsteady walking, recurrent pneumonia, and easily progression to respiratory failure requiring mechanical ventilation. Two juvenile-onset GSD II patients, as reported by Orlikowski et al. [13], who had severe respiratory symptoms at the baseline, remained on continuous ventilation support $24 \mathrm{~h}$ a day throughout the study. Once GSD II patients develop pneumonia and respiratory failure needing mechanical ventilation, it is very difficult to achieve weaning from mechanical ventilation. In GSD II, the disease severity depends on the disease type (infantile, juvenile or adult-onset) [12], the presence of cardiomyopathy, and the crossreactive immunological material (CRIM) status [14].

ERT can improve muscle strength and respiratory function [15] and prevent the deterioration of respiratory function [16]. Infantile-onset GSD II usually presents with hypertrophic cardiomyopathy and such patients die before age 1 year, if not treated with ERT. For infantile-onset GSD II patients, the earlier ERT is administered the better [17]. Broomfield et al. [11] studied 33 United Kingdom patients with infantile-onset GSD II and found that $70 \%$ of them had radiological signs of focal pulmonary collapse and 27\% (9/33) required mechanical ventilation. Chakrapani et al. [18] analyzed 20 infantile-onset GSD II patients who received ERT. These 20 patients were divided into two groups according to whether or not mechanical ventilation lasted longer than 2 weeks. All eight cases requiring ventilation for $>2$ weeks eventually required long-term ventilation, and two of them died. Another study [19] showed that only $50 \%$ of ICU patients who were treated with mechanical ventilation for more than 14 days were successfully weaned off mechanical ventilation, and only $19 \%$ were discharged home. In our study, three patients with infantile-onset GSD II received mechanical ventilation for longer than 2 weeks. Patient 5 was successfully weaned from ventilation, and Patients 4 and 6 died.

Parini et al. [20] studied 28 infantile-onset GSD II patients from 13 Italian centres who started ERT within the first year of life and were followed for a median period of 71 months (5 years 11 months). This study confirmed the better outcome of the CRIM-positive patients but at the same time, showed the inability of the current therapeutic approach to reverse or stabilize the disease progression. So the long-term effectiveness of
ERT is still not completely defined. Larger multicentre studies are needed as well as the development of new therapeutic approaches [20].

Deroma et al. [21] also studied eight Italian juvenile-onset GSD II patients treated with ERT for at least 72 months. The respiratory function of four patients showed a slight improvement and four patients remained stable; two of them already required ventilator support. In our study, three patients with juvenile-onset GSD II required mechanical ventilation. The respiratory function of three patients improved, one patient required tracheal intubation and mechanical ventilation at home, and two patients were successfully weaned from ventilation. Juvenile-onset GSD II patients have previously been reported on in individual case studies or small series, and our juvenile-onset GSD II patients cannot be compared to them, due to the vastly differing ages.

Falk et al. [22] showed that respiratory dysfunction in GSD II is mainly caused by significant pathological alterations at the neuromuscular junctions of the diaphragm as prominent features of disease pathology. Despite the cardiac and skeletal muscle, and force vital capacity improvements $[18,21,23]$, slowly progressive neuromuscular weakness persists, which leads to diaphragmatic paralysis $[24,25]$. In our study, most of the patients were successfully weaned from the ventilator after ERT. This shows that ERT can improve lung function. In Patient 1, in whom weaning from invasive mechanical ventilation failed all six times, diaphragm dysfunction may have been the cause. ICU-acquired respiratory muscle dysfunction [26] may have been another cause of unsuccessful weaning in Patient 1.

Smith et al. [27] found that a combined human trial of diaphragmatic gene therapy and inspiratory muscle conditioning exercise was beneficial to the dynamic motor function of the diaphragm in some children with infantile-onset GSD II. Todd et al. [28] found that correcting neuromuscular deficits with gene therapy may be essential to the successful correction of neuromuscular function in GSD II. Smith et al. [29] showed that neuromuscular activity via diaphragm pacing could promote weaning from mechanical ventilation in patients with Pompe disease who are unresponsive to conventional, muscle-directed treatment.

Remiche et al. [30] showed that there was no significant correlation between the level of GAA residual activity and the presence of a "severe" mutation on the second allele. Leukocyte or muscle GAA residual activity was not correlated to a protective effect (e.g., one patient had very low residual activity but her symptoms began presenting only at age 61 years) [30]. Previous research has shown [9] that male sex is a prognostic factor for poor respiratory outcomes. In our study, Patients 1 and 3 were female, with nearly the same GAA activity level. 
Patient 2, the younger brother of Patient 3, presented with severe respiratory involvement and weaning from mechanical ventilation proved more difficult than in his older sister. Patients 2 and 3 had the same genotype, but the younger brother who had higher GAA activity levels presented with severe respiratory involvement leading to more severe weaning difficulties. In addition, patient 5, who had zero GAA activity, was successfully weaned from mechanical ventilation twice. This shows that there maybe no significant correlation between severe clinical manifestations such as respiratory symptoms and GAA enzyme activity.

Enzyme therapy and immune response are related to a CRIM status [14, 20]. CRIM negative/positive with high levels of antibodies are a predictable sign of poor outcome in infantile form. CRIM-positive patients seem to have better clinical outcomes than CRIM-negative patients $[14,20]$, because their antibody titers are generally lower than those of CRIM-negative patients. Yang et al. [31] who reported on 14 infantile-onset patients who were CRIM-positive showed that $12 / 14$ patients had the most commonly found mutation--c.1935 C > A. Juvenile form are by definition CRIM positive because they present residual enzymatic activity. However, none of our patients were tested for their CRIM status. We believe five of our six patients may have had a CRIMpositive status as they had the c.1935 C > A mutation [31]; this may be a reason for their better clinical outcomes.

Invasive mechanical ventilation is a lifesaving intervention for GSD II patients with respiratory failure. However, prolonged mechanical ventilation is associated with pulmonary complications, increased lengths of hospital stay, and higher mortality. Non-invasive ventilation is a weaning strategy for mechanical ventilation in patients with weaning difficulties. The Breathe Randomized Clinical Trial [32] showed that noninvasive ventilation could facilitate early liberation in patients in whom weaning from invasive mechanical ventilation was difficult. Non-invasive ventilation may reduce the durations of mechanical ventilation and ICU stays more effectively than conventional weaning. With the use of the sequential invasive-noninvasive mechanical ventilation weaning strategy, most of our patients were successfully weaned.

Patients requiring mechanical ventilation are at a risk for mental stress as they are aware that their ability to breathe totally depends on mechanical ventilation. Rose et al. [33] reported that $29 \%$ of prolonged mechanical ventilation patients were routinely referred for psychiatric/psychological treatment. Patients with emotional stress are likelier to experience weaning failure and death. Longer ICU visiting hours [34] and music therapy [35] can reduce the symptoms of anxiety and depression when weaning from mechanical ventilation. Efficient communication between patients and medical staff concerning the details of weaning from ventilation is essential in instilling confidence in the process. In our study, we provided all of the above to assist in weaning.

Recent studies [36-38] have shown that respiratory muscle training is an adjunctive treatment for respiratory weakness in late-onset GSD II. Malnutrition is associated with the duration of mechanical ventilation in critically ill children [39]. Malnutrition is a predictor of prolonged mechanical ventilation. All our patients had malnutrition, with body mass index values lower than $18 \mathrm{~kg} / \mathrm{m}^{2}$; their nutritional status improved after enhanced nutritional support provision, which may have increased the tolerance to weaning from ventilation. We also used respiratory muscle training, which proved to be effective. Few articles have focused on weaning from mechanical ventilation in GSD II. ERT can improve muscle strength and respiratory function and prevent the deterioration of respiratory function, but it cannot reverse or stabilize disease progression in patients with weaning difficulties. We recommended a weaning strategy to guide clinicians to extubate patients who were difficult to wean to noninvasive ventilation, when the condition of weaning was met. The comprehensive treatment described in this paper, which included a sequential invasive-noninvasive mechanical ventilation weaning strategy and ERT in patients with weaning difficulties, was efficient and may be worth popularizing.

\section{Abbreviations}

ABG: Arterial blood gas; BiPAP: Biphasic positive airway pressure; BMI: Body Mass Index; CPAP: Continuous positive airway pressure; CRIM: Cross reactive immunological material; CT: Computed Tomography; ERT: Enzyme replacement therapy; $\mathrm{F}$ : Female; $\mathrm{FiO}_{2}$ : Fraction of inspired oxygen; GAA: Acid alpha-glucosidase; GSD II: Glycogen storage disease type II; HFNC: High-flow nasal cannula; ICU: Intensive Care Unit; IV: Invasive ventilation; LL: Lower-limb muscle strength; LVEdD: Left-ventricular end-diastolic diameter; M: Male; MHC: Minimal head control; MRC: Medical Research Council; MV: Mechanical ventilation; NA: Not Applicable; NGT: Naso-gastric tube; NIV: Noninvasive ventilation; NT: Not tested; P: Patient no; $\mathrm{PaCO}_{2}$ : Partial pressure of carbon dioxide; $\mathrm{PaO}_{2}$ : Partial pressure of oxygen; PBLC: Peripheral blood leukocytes; PH: Potential Hydrogen; PS: Pressure support; $\mathrm{SaO}_{2}$ : Arterial oxygen saturation; SD: Standard deviation; UL: Upper-limb muscle strength

\section{Acknowledgements}

We thank the family for their contribution to this study and thank Editage (www.editage.com) for English language editing.

\section{Authors' contributions}

WT conceptualized and designed the study, reviewed and revised the manuscript. LLX and HJB carried out the initial analyses and drafted the initial manuscript. YXP, XQH and YJL were responsible for the treatment of patients. LDZ and HMH coordinated and supervised the data collection. SPL and $C Z$ critically reviewed the manuscript. All authors read and approved the final manuscript.

\section{Funding}

This study was supported by 2010 National Clinical Key Specialty Construction Project (Grant No.2011-872), Guangdong Science and Technology Project (Grant No. 2013 B02180 0276) and Scientific Research Special Project of Science and Technology Program of Guangzhou (Grant No.201510010148). 


\section{Availability of data and materials}

All datasets generated for this study are included in the manuscript and the supplementary files.

\section{Ethics approval and consent to participate}

This study was approved by the ethics committee of the First Affiliated Hospital, Sun Yat-sen University. Signed informed consent was obtained from all the parents of patients diagnosed with GSD II.

\section{Consent for publication}

Signed informed consent forms were obtained from the parents of the children.

\section{Competing interests}

The author declares that they have no competing interests.

\section{Author details}

'Department of PICU, The First Affiliated Hospital, Sun Yat-Sen University, 58 Zhongshan Second Road, Guangzhou, Guangdong 510080, People's Republic of China. ${ }^{2}$ Department of Cardiovascular pediatrics, The First Affiliated Hospital, Sun Yat-Sen University, 58 Zhongshan Second Road, Guangzhou, Guangdong 510080, People's Republic of China. ${ }^{3}$ Department of Neurology, The First Affiliated Hospital, Sun Yat-Sen University, 58 Zhongshan Second Road, Guangzhou, Guangdong 510080, People's Republic of China.

Received: 12 December 2018 Accepted: 30 July 2019

\section{Published online: 22 August 2019}

\section{References}

1. Kohler L, Puertollano R, Raben N. Pompe disease: from basic science to therapy. Neurotherapeutics. 2018;15:928-42.

2. De Jonghe B, Bastuji-Garin S, Durand MC, Malissin I, Rodrigues P, Cerf C, et al. Groupe de Réflexion et d'Etude des Neuromyopathies en Réanimation. Respiratory weakness is associated with limb weakness and delayed weaning in critical illness. Crit Care Med. 2007:35:2007-15.

3. DeRuisseau LR, Fuller DD, Qiu K, DeRuisseau KC, Donnelly WH Jr, Mah C, et al. Neural deficits contribute to respiratory insufficiency in Pompe disease. Proc Natl Acad Sci U S A. 2009;106:9419-24.

4. Busl KM, Ouyang B, Boland TA, Pollandt S, Temes RE. Prolonged mechanical ventilation is associated with pulmonary complications, increased length of stay, and unfavorable discharge destination among patients with subdural hematoma. J Neurosurg Anesthesiol. 2015;27:31-6.

5. Milverton J, Newton S, Merlin T. The effectiveness of enzyme replacement therapy for juvenile-onset Pompe disease: a systematic review. J Inherit Metab Dis. 2018. https://doi.org/10.1007/s10545-018-0198-8 [Epub ahead of print] Review.

6. Chen M, Zhang L, Quan S. Enzyme replacement therapy for infantile-onset Pompe disease. Cochrane Database Syst Rev. 2017;11:CD011539. https://doi. org/10.1002/14651858.

7. Thomas AN, Hagan JL, Lingappan K. Noninvasive ventilation strategies: which to choose? J Perinatol. 2018;38:447-50.

8. Van der Beek NA, Hagemans ML, Reuser AJ, Hop WC, Van der Ploeg AT, Van Doorn PA, et al. Rate of disease progression during long-term follow-up of patients with late-onset Pompe disease. Neuromuscul Disord. 2009:19(2):113-7.

9. Van der Beek NA, van Capelle Cl, van der Velden-van Etten Kl, Hop WC, van den Berg B, Reuser AJ, et al. Rate of progression and predictive factors for pulmonary outcome in children and adults with Pompe disease. Mol Genet Metab. 2011:104(1-2):129-36.

10. Kishnani PS, Hwu WL, Mandel H, Nicolino M, Yong F, Corzo D. A retrospective, multinational, multicenter study on the natural history of infantile-onset Pompe disease. J Pediatr. 2006;148:671-6.

11. Broomfield A, Fletcher J, Davison J, Finnegan N, Fenton M, Chikermane A, et al. Response of 33 UK patients with infantile-onset Pompe disease to enzyme replacement therapy. J Inherit Metab Dis. 2016;39:261-71.

12. Bembi B, Cerini E, Danesino C, Donati MA, Gasperini S, Morandi L, et al. Diagnosis of glycogenosis type II. Neurology. 2008;71(23 Suppl 2):S4-11.

13. Orlikowski D, Pellegrini N, Prigent $H$, Laforêt $P$, Carlier R, Carlier $P$, et al. Recombinant human acid alpha-glucosidase (rhGAA) in adult patients with severe respiratory failure due to Pompe disease. Neuromuscul Disord. 2011; 21(7):477-82.
14. Van Gelder CM, Hoogeveen-Westerveld M, Kroos MA, Plug I, van der Ploeg AT, Reuser AJ. Enzyme therapy and immune response in relation to CRIM status: the Dutch experience in classic infantile Pompe disease. J Inherit Metab Dis. 2015;38(2):305-14.

15. Vianello A, Semplicini C, Paladini L, Concas A, Ravaglia S, Servidei S, et al. Enzyme replacement therapy improves respiratory outcomes in patients with late-onset type II glycogenosis and high ventilator dependency. Lung. 2013;191:537-44.

16. Schoser B, Stewart A, Kanters S, Hamed A, Jansen J, Chan K, et al. Survival and long-term outcomes in late-onset Pompe disease following alglucosidase alfa treatment: a systematic review and meta-analysis. J Neurol. 2017;264:621-30

17. Yang CF, Liu HC, Hsu TR, Tsai FC, Chiang SF, Chiang CC, et al. A large-scale nationwide newborn screening program for Pompe disease in Taiwan: towards effective diagnosis and treatment. Am J Med Genet A. 2014; 164A(1):54-61. https://doi.org/10.1002/ajmg.a.36197.

18. Chakrapani A, Vellodi A, Robinson P, Jones S, Wraith JE. Treatment of infantile Pompe disease with alglucosidase alpha: the UK experience. J Inherit Metab Dis. 2010:33:747-50.

19. Damuth E, Mitchell JA, Bartock JL, Roberts BW, Trzeciak S. Long-term surviva of critically ill patients treated with prolonged mechanical ventilation: a systematic review and meta-analysis. Lancet Respir Med. 2015;3:544-53.

20. Parini R, De Lorenzo P, Dardis A, Burlina A, Cassio A, Cavarzere P, et al. Long term clinical history of an Italian cohort of infantile onset Pompe disease treated with enzyme replacement therapy. Orphanet J Rare Dis. 2018;13:32. https://doi.org/10.1186/s13023-018-0771-0.

21. Deroma L, Guerra M, Sechi A, Ciana G, Cisilino G, Dardis A, et al. Enzyme replacement therapy in juvenile glycogenosis type II: a longitudinal study. Eur J Pediatr. 2014;173:805-13. https://doi.org/10.1007/s00431-013-2258-2.

22. Falk DJ, Todd AG, Lee S, Soustek MS, EIMallah MK, Fuller DD, et al. Peripheral nerve and neuromuscular junction pathology in Pompe disease. Hum Mol Genet. 2015;24:625-36.

23. Joanne M, Skye N, Tracy M. The effectiveness of enzyme replacement therapy for juvenile-onset Pompe disease: a systematic review. J Inherit Metab Dis. 2019;42(1):57-65. https://doi.org/10.1002/jimd.12027 Review.

24. Smith BK, Corti M, Martin AD, Fuller DD, Byrne BJ. Altered activation of the diaphragm in late-onset Pompe disease. Respir Physiol Neurobiol. 2016;222: $11-5$

25. Wens SC, Ciet P, Perez-Rovira A, Logie K, Salamon E, Wielopolski P, et al. Lung MRI and impairment of diaphragmatic function in Pompe disease. BMC Pulm Med. 2015;15:54.

26. Jonkman AH, Jansen D, Heunks LM. Novel insights in ICU-acquired respiratory muscle dysfunction: implications for clinical care. Crit Care. 2017;21:64.

27. Smith BK, Martin AD, Lawson LA, Vernot V, Marcus J, Islam S, et al. Inspiratory muscle conditioning exercise and diaphragm gene therapy in Pompe disease: clinical evidence of respiratory plasticity. Exp Neurol. 2017 287:216-24.

28. Todd AG, McElroy JA, Grange RW, Fuller DD, Walter GA, Byrne BJ, et al. Correcting neuromuscular deficits with gene therapy in Pompe disease. Ann Neurol. 2015;78:222-34.

29. Smith BK, Fuller DD, Martin AD, Lottenberg L, Islam S, Lawson LA, et al. Diaphragm pacing as a rehabilitative tool for patients with Pompe disease who are ventilator-dependent: case series. Phys Ther. 2016:96:696-703.

30. Remiche G, Ronchi D, Magri F, Lamperti C, Bordoni A, Moggio M, et al. Extended phenotype description and new molecular findings in late onset glycogen storage disease type II: a northern Italy population study and review of the literature. J Neurol. 2014;261:83-97.

31. Yang CF, Yang CC, Liao HC, Huang LY, Chiang CC, Ho HC, et al. Very early treatment for infantile-onset Pompe disease contributes to better outcomes. J Pediatr. 2016:169:174-80.e1.

32. Perkins GD, Mistry D, Gates S, Gao F, Snelson C, Hart N, et al. Effect of Protocolized weaning with early Extubation to noninvasive ventilation vs invasive weaning on time to liberation from mechanical ventilation among patients with respiratory failure: the breathe randomized clinical trial. JAMA 2018;320:1881-8.

33. Rose L, Fowler RA, Fan E, Fraser I, Leasa D, Mawdsley C, et al. Prolonged mechanical ventilation in Canadian intensive care units: a national survey. J Crit Care. 2015:30:25-31.

34. Fumis RR, Ranzani OT, Faria PP, Schettino G. Anxiety, depression, and satisfaction in close relatives of patients in an open visiting policy intensive care unit in Brazil. J Crit Care. 2015;30:440.e1-6. 
35. Lee CH, Lee CY, Hsu MY, Lai CL, Sung YH, Lin CY, et al. Effects of music intervention on state anxiety and physiological indices in patients undergoing mechanical ventilation in the intensive care unit. Biol Res Nurs. 2017:19:137-44.

36. Boentert M, Prigent $H$, Várdi K, Jones HN, Mellies U, Simonds AK, et al. Practical Recommendations for Diagnosis and Management of Respiratory Muscle Weakness in Late-Onset Pompe Disease. Int J Mol Sci. 2016;17(10).

37. Jones HN, Crisp KD, Robey RR, Case LE, Kravitz RM, Kishnani PS. Respiratory muscle training (RMT) in late-onset Pompe disease (LOPD): effects of training and detraining. Mol Genet Metab. 2016;117:120-8.

38. Jones HN, Crisp KD, Moss T, Strollo K, Robey R, Sank J, et al. Effects of respiratory muscle training (RMT) in children with infantile-onset Pompe disease and respiratory muscle weakness. J Pediatr Rehabil Med. 2014;7: 255-65.

39. Grippa RB, Silva PS, Barbosa E, Bresolin NL, Mehta NM, Moreno YM. Nutritional status as a predictor of duration of mechanical ventilation in critically ill children. Nutrition. 2017;33:91-5.

\section{Publisher's Note}

Springer Nature remains neutral with regard to jurisdictional claims in published maps and institutional affiliations.

Ready to submit your research? Choose BMC and benefit from:

- fast, convenient online submission

- thorough peer review by experienced researchers in your field

- rapid publication on acceptance

- support for research data, including large and complex data types

- gold Open Access which fosters wider collaboration and increased citations

- maximum visibility for your research: over $100 \mathrm{M}$ website views per year

At $\mathrm{BMC}$, research is always in progress.

Learn more biomedcentral.com/submissions 